\title{
Respiratory Care of Patients With Neuromuscular Disease
}

\author{
Joshua O Benditt
}

\author{
Introduction \\ Effects of NMD on the Respiratory System \\ Respiratory Muscle Strength \\ Cough Function Abnormalities \\ Sleep Abnormalities \\ Reductions in Respiratory System Compliance \\ Respiratory Treatment for NMD \\ Nocturnal Ventilatory Support \\ Devices \\ Interfaces \\ Effectiveness \\ Diurnal Ventilation \\ Cough Management \\ Sialorrhea \\ Respiratory System Compliance \\ Summary
}

Neuromuscular diseases are a heterogeneous group of neurologic diseases that affect a number of neural structures including the motor nerves, neuromuscular junctions, or the muscles themselves. Although many of the diseases are rare, the total number of individuals who present to a pulmonologist or respiratory care provider is significant. Approaches to care include regular and careful clinical follow-up of symptoms of sleep-disordered breathing, daytime hypoventilation, as well as cough and swallowing effectiveness. Noninvasive support with nocturnal mask ventilation and a pressure support device can be extraordinarily helpful and delay daytime ventilatory failure. When daytime ventilatory failure develops, other noninvasive methods are available for portable assistance. Support of cough function with manual assistance, a resuscitator bag, and/or mechanical insufflation-exsufflation can help prevent and treat infection. Referral for swallowing evaluation and treatment is very important for those with impaired bulbar function. This comprehensive respiratory care approach to individuals with neuromuscular disease and respiratory system involvement is essential to maintaining the health and longevity of these individuals. Key words: noninvasive ventilation; BPAP; mouthpiece ventilation; sip ventilation; mechanical insufflation-exsufflation; amyotrophic lateral sclerosis; muscular dystrophy; myotonic dystrophy; spinal cord injury. [Respir Care 2019;64(6):679-688. (c) 2019 Daedalus Enterprises]

\section{Introduction}

Neuromuscular diseases (NMDs) are those neurologic diseases that affect the functioning of muscles directly or

\footnotetext{
Dr Benditt is affiliated with Pulmonary and Critical Care Medicine, University of Washington Medical Center, Seattle, Washington.

Dr Benditt discloses a relationship with Ventec Life Systems.

Dr Benditt presented a version of this paper at the 57th RESPIRATORY CARE Journal Conference, held June 14-15, 2018, in St Petersburg, Florida.
}

indirectly through effects on the nerves or neuromuscular junctions. Although the incidence and prevalence of these diseases around the world is difficult to ascertain, a recent study from the Republic of Ireland puts the prevalence of

\footnotetext{
Correspondence: Joshua O Benditt MD, Pulmonary and Critical Care Medicine, University of Washington Medical Center, Box 356522, Seattle, WA 98195-06522. E-mail: benditt@uw.edu.
}

DOI: $10.4187 /$ respcare. 06827 


\section{Respiratory CARE of Patients With NMD}

Table 1. Examples of Neuromuscular Diseases and Where They Affect the Neuromuscular System

\begin{tabular}{llll}
\hline \hline \multicolumn{1}{c}{ Spinal Cord } & \multicolumn{1}{c}{ Motor Nerves } & \multicolumn{1}{c}{ Neuromuscular Junction } & \multicolumn{1}{c}{ Muscle } \\
\hline Trauma & Amyotrophic lateral sclerosis & Myasthenia gravis & Muscular dystrophies \\
Infarction or hemorrhage & Post-polio syndrome & Lambert-Eaton myasthenic syndrome & Myotonic dystrophy \\
Demyelinating disease & Spinal muscular atrophy & Antibiotics & Poly- and dermatomyositis \\
Disc compression & Primary lateral sclerosis & Anti-cholinesterase inhibitors & Glycogen storage diseases \\
Syringomyelia & Charcot-Marie tooth disease & Corticosteroids & Pompe's \\
Neoplasm & Vasculitides & Quinidine & McArdle disease \\
& Diabetes & Lithium & Tarui's disease \\
& Porphyria & Anti-rheumatics & Thick filament myopathy \\
& Uremia & & Mitochondrial myopathy \\
& & & Nemaline body myopathy \\
\hline
\end{tabular}

NMDs at 62.6/100,000 (95\% CI 59.95-65.24). ${ }^{1}$ Because many of these diseases are hereditary, it is likely that the incidence and prevalence vary widely in other countries. Table 1 lists some of the disorders that may be seen by the respiratory practitioner.

For the practitioner of respiratory medicine, a number of other diseases that are not traditionally considered NMDs by neurologists, such as spinal cord injury, stroke, and some central nervous system conditions, may have similar or related respiratory effects, and thus many of the issues discussed in this article may apply to a much larger patient group.

\section{Effects of NMD on the Respiratory System}

\section{Respiratory Muscle Strength}

Each NMD will have a different and specific natural history, but some common themes can be seen. Decreased ventilatory muscle strength with a reduction in vital capacity is often observed, and this can be caused by a reduction in inspiratory muscle strength alone or in combination with a reduction in expiratory muscle strength with an increase in residual volume. The onset and progression of the weakness is quite variable and can be acute, as in the setting of spinal cord injury, or very gradual, as in milder forms of muscular dystrophy.

Measurements of respiratory muscle strength are important to assess over time in patients with NMDs. The most commonly used measurement is vital capacity, which is a global assessment of respiratory muscle capacity that includes both inspiratory and expiratory muscle function. Supine vital capacity can be very helpful in assessing diaphragm weakness. A drop in vital capacity while supine of $>19 \%$ suggests diaphragm weakness, and patients with bilateral diaphragm paralysis may drop by up to $50 \% .^{2}$ Sniff nasal inspiratory pressure appears to be a reproducible measurement that can accurately predict nocturnal desaturations and respira- tory failure in patients with amyotrophic lateral sclerosis (ALS). ${ }^{3}$ This method has the benefit of avoiding the need for a firm mouth seal in patients with bulbar dysfunction. It has been suggested that recording multiple tests may be the most appropriate way to follow patients with NMDs. ${ }^{4}$ In our clinic, we see patients and perform these measurements every 3-6 months.

\section{Cough Function Abnormalities}

Impairment of cough function is common in NMDs and is caused by both inspiratory and expiratory muscle weakness as well as by impaired glottic function. Reduction in inspiratory muscle strength leads to a reduction in the volume of intrathoracic gas available to remove secretions from airways. Reduction in expiratory muscle strength also reduces FVC, but more importantly it reduces the intraairway gas compression that is responsible for the explosive exhalation of gas during the exhalatory phase of cough. Finally, the glottic muscles of the larynx are critical to maintaining gas under high pressure in the airway while the abdominal muscles contract and then instantaneously release the gas through the airway. ${ }^{5}$ Cough function is crucial to maintain airway clearance and to prevent infection and the spiral of progressive respiratory failure due to increased work of breathing, hypoxemia, and hypercarbia. Cough function is best assessed by measuring the cough peak flow, which can be performed easily with a spirometer or a peak flow meter (Fig. 1). ${ }^{6}$ A value of $160 \mathrm{~L} / \mathrm{min}$ or less is associated with inadequate clearance of secretions. A measured value of $\leq 270 \mathrm{~L} / \mathrm{min}$ when a patient is well and without infection has been reported to drop to values $\leq 160 \mathrm{~L} / \mathrm{min}$ during illness and should prompt increased focus on cough assistance. ${ }^{7}$ Patients with cough failure and bulbar involvement may also present with an inability to manage secretions, which may make management difficult. ${ }^{8}$ This is not due to the volume of secretions, rather to difficulty with management of the secretions through swallowing or expectoration. 


\section{Respiratory CARE of PATIENTS With NMD}
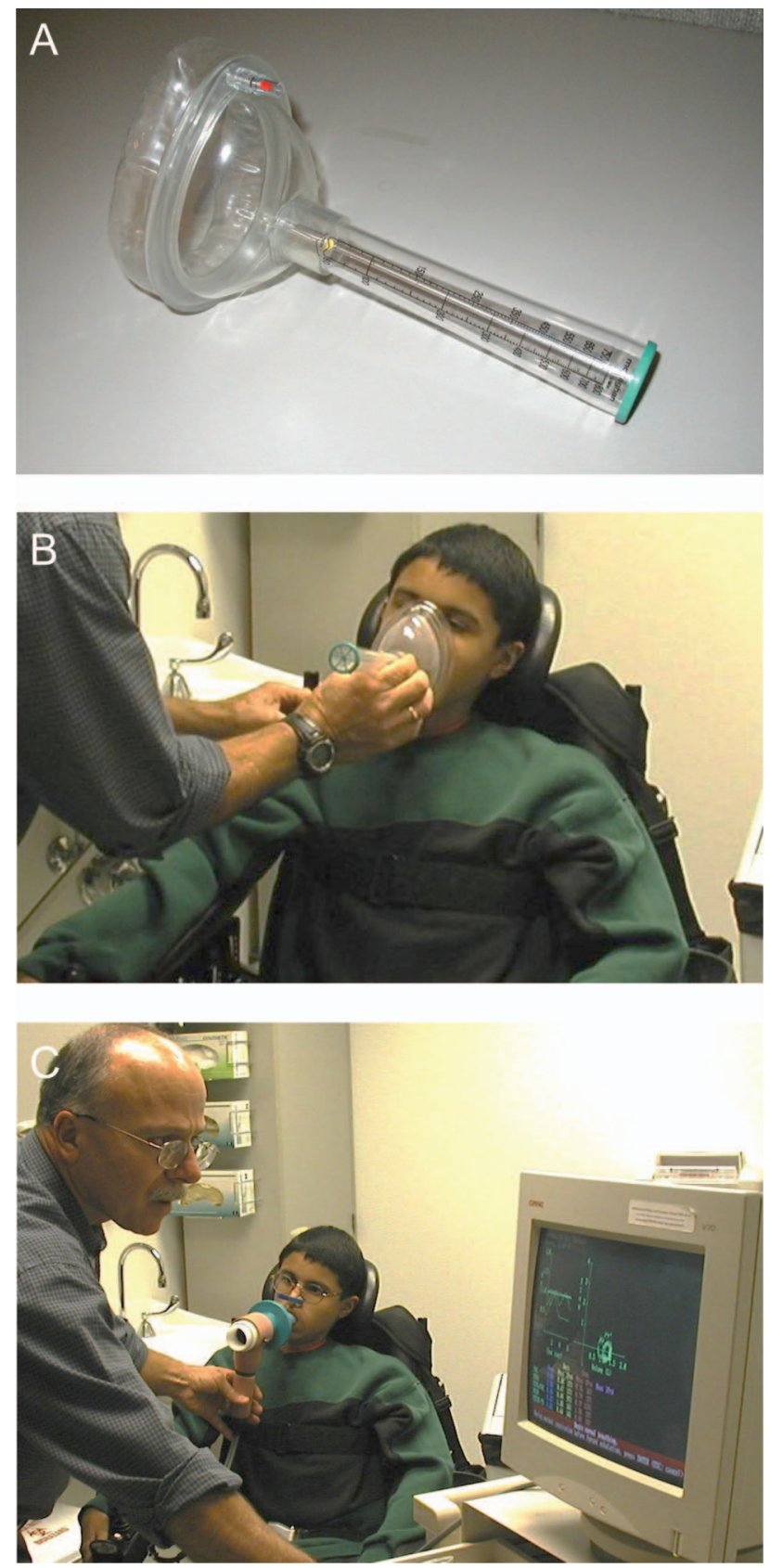

Fig. 1. Measuring cough peak flow. A: Asthma peak flow meter set up to measure peak cough flow with mask. B: Measuring cough peak flow with asthma peak flow meter and mask. C: Measuring cough peak flow with computerized spirometer. With permission. From Reference 32.

\section{Sleep Abnormalities}

Sleep abnormalities are very common in individuals with NMDs. ${ }^{9}$ Hypoventilation, central apneas, and obstructive events can be seen in these patients. Sleep-disordered breathing tends to increase with decreased vital capacity due to respiratory muscle weakness. ${ }^{10,11}$ During sleep, tidal
Table 2. Criteria for Coverage of Nocturnal Noninvasive Ventilation for NMDs

While breathing, the patient's normal $\mathrm{F}_{\mathrm{IO}_{2}}$

a. Diurnal, awake $\mathrm{P}_{\mathrm{aCO}} \geq 45 \mathrm{~mm} \mathrm{Hg}$

b. Demonstrates sleep desaturation $\leq 88 \%$ for 5 consecutive minutes during nocturnal oximetry

Exhibits

c. Maximal inspiratory pressure is $>-60 \mathrm{~cm} \mathrm{H}_{2} \mathrm{O}$

d. FVC $<50 \%$ predicted

Patient must have a neuromuscular disease (NMD) diagnosis, symptoms of sleep disturbance, and at least one of a, b, c, or d. COPD cannot contribute significantly to the patient's pulmonary limitation. From Reference 20.

volume drops by approximately $10 \%$, and expiratory reserve volume also drops. These low lung volumes increasing may be a risk factor for obstructive sleep apnea because lung elastic recoil is reduced at lower lung volumes, thus potentially reducing traction and stability of the upper airway. ${ }^{12}$ Lower lung volumes also contribute to more significant desaturation during sleep-disordered events. In addition to muscle weakness leading to hypoventilation, there may be associated abnormalities in the central drive to breathe, particularly in diseases such as myotonic dystrophy and the muscular dystrophies. ${ }^{13,14}$ Sleep-disordered breathing is very common in individuals with NMD and is generally seen prior to diurnal hypoventilation and respiratory failure. It is critical to perform a sleep review, including questions regarding daytime hypersomnolence, frequent nocturnal awakenings for nocturia or other reasons, morning headaches, and decreases in concentration or mental function. Patients with diaphragm weakness may notice dyspnea while lying flat. ${ }^{15}$ In addition, measurement of $\mathrm{CO}_{2}$ by arterial blood gas, end-tidal $\mathrm{PCO}_{2}\left(\mathrm{P}_{\mathrm{ETCO}_{2}}\right)$, or transcutaneous $\mathrm{CO}_{2}$ should be made during clinic visits. Elevated levels suggest the presence of sleep-disordered breathing. ${ }^{4}$ Sleep studies are considered to be the accepted standard for assessing sleep-disordered breathing and adjusting nocturnal noninvasive ventilation. However, patients with NMDs can present difficulties for sleep labs because of the frequent need of a Hoyer lift, attendant care, suction, and other equipment that a NMD patient's condition may require. Therefore, having a high pretest probability prior to a sleep study by having diurnal $\mathrm{P}_{\mathrm{aCO}}$ $>45 \mathrm{~mm} \mathrm{Hg}$ or a base excess $>4 \mathrm{mEq}$ can be helpful in screening. ${ }^{4}$ Portable home sleep studies have not been well validated in this population. It should be noted for NMDs that a formal sleep study is not required for payment for and initiation of noninvasive ventilator support. A patient with a neuromuscular diagnosis who has symptoms of sleep-disordered breathing and meets one of the criteria in Table 2 qualifies for a nocturnal noninvasive support device. 


\section{Reductions in Respiratory System Compliance}

Patients with NMDs often have a reduction in respiratory system compliance. This can be due to one of several factors. The progressive loss of respiratory system volume results in alveolar collapse and microatelectasis that reduces lung compliance. ${ }^{16}$ In addition, there are changes in both the chest wall muscles and the joints of the thoracic cage that can result in significant reductions in chest wall compliance. ${ }^{17}$ Finally, some NMDs, such as post-polio syndrome, spinal muscular atrophy, and muscular dystrophies, are associated with kyphoscoliosis, which results in low lung volumes and spinal rigidity that can contribute to a very stiff and poorly compliant chest wall. ${ }^{18}$ Reduction in compliance of the respiratory system contributes to an increase in the elastic work of breathing that stresses already weak muscles and may increase the risk of respiratory failure.

\section{Respiratory Treatment for NMD}

\section{Nocturnal Ventilatory Support}

Other than acute diseases such as myasthenia gravis or Guillain-Barré syndrome, most progressive NMDs result in nocturnal hypoventilation that precedes diurnal respiratory failure. Therefore, a high index of suspicion for sleepdisordered breathing is key, as are measurements of FVC (upright and supine), maximum inspiratory pressure $\left(\mathrm{P}_{\text {Imax }}\right)$, and an estimate of $\mathrm{P}_{\mathrm{aCO}}$ by arterial blood gas, $\mathrm{P}_{\mathrm{ETCO}_{2}}$, or transcutaneous $\mathrm{CO}_{2}$. If a patient presents with sleep symptoms as noted above and has either a positive polysomnogram or meets the criteria in Table 2, noninvasive ventilation should be started. ${ }^{19}$ These are the guidelines used in the United States; other countries use different criteria for initiating noninvasive ventilation.

\section{Devices}

Noninvasive ventilation is generally the preferred method of support because it is less expensive, avoids the surgery associated with tracheostomy, and is often preferred by patients. Appropriate ventilatory support devices for nocturnal support most commonly are devices with bi-level capability with a backup rate. A number of modes of bi-level support are available, including pressure support, pressure control, and volume-targeted modes such as average volume-assured pressure support (AVAPS) and intelligent volume-assured pressure support. It has not been determined at this time which if any of these modes is clinically superior. One small retrospective study of subjects with ALS compared AVAPS to pressure support and found that tidal volumes were slightly higher in subjects using AVAPS compared to bi-level support, but minute ventilation, breathing frequency, and hours of use per day were not statistically different. ${ }^{20}$ Volume ventilation has also been used for ventilating patients with NMDs, although this is less common because many patients do not tolerate this mode of ventilation. ${ }^{21}$ CPAP is not appropriate for patients with NMDs because hypoventilation and central events are very common, which CPAP will not treat.

The most commonly used mode is bi-level with a backup rate (BPAP S/T). Device settings to set up bi-level support with a backup rate will vary, but pressures are usually set with an expiratory positive airway pressure starting at $4 \mathrm{~cm} \mathrm{H}_{2} \mathrm{O}$ and an inspiratory pressure adjusted to produce a tidal volume of $6-8 \mathrm{~mL} / \mathrm{kg}$. Most of the devices give volume readouts in real time or they can be downloaded from overnight recording. A backup rate of 10-12 breaths is often used, but this can be adjusted per patient comfort. ${ }^{22}$ Inspiratory pressure can be increased gradually if symptoms or elevated $\mathrm{CO}_{2}$ levels during the daytime persist. Inspiratory positive airway pressure levels of $20 \mathrm{~cm} \mathrm{H}_{2} \mathrm{O}$ or more are occasionally needed. If appropriate settings cannot be achieved in the out-patient setting, in-lab titration sleep studies can be arranged. ${ }^{9}$

\section{Interfaces}

For nocturnal ventilatory support, mask interfaces are the most commonly used. Mask interface technologies have developed dramatically, and many of the previous complications such as skin breakdown, significant air leaks, and patient intolerance have decreased. There are a number of mask options, including nasal masks, oronasal masks, total face masks, and lip-seal devices. ${ }^{23}$ Selection of the mask should depend on patient comfort and preference, and a number of masks should be tried. Many patients with NMDs often prefer a nasal mask because total face masks can cause claustrophobia and, if limb weakness is significant, may not be easily removed by the patient. Nasal masks are associated with mouth leak in some patients, and the use of a chin strap can be helpful. ${ }^{24}$ Having more than one type of mask to use may be helpful for the patient in that it may reduce the risk of skin breakdown in one area. ${ }^{25}$

\section{Effectiveness}

Monitoring of the effectiveness of nocturnal support in the individual should include history assessment, looking for resolution or improvement in sleep symptoms, and normalization of diurnal $\mathrm{CO}_{2}$ levels. Downloads from the devices obtained over the Internet or via memory cards can be helpful in adjusting settings. Titration sleep studies may be needed if settings do not result in an adequate response. ${ }^{26}$ 


\section{Respiratory CARe of Patients With NMD}

The effectiveness of nocturnal NIV in prolonging survival in the NMD population has been evaluated most commonly in the context of ALS, where a number of prospective and retrospective cohort studies have been conducted. ${ }^{27}$ One randomized trial showed a survival benefit in subjects with ALS. ${ }^{28}$ Because there is no truly effective treatment for ALS, using NIV both for survival and palliation seems reasonable. Two studies in subjects with Duchenne muscular dystrophy showed a very significant increase in life span over the period of time that NIV was introduced in this patient population. ${ }^{29,30}$ Some authors have felt that truly randomized studies with sham ventilation may not be ethical in this patient population. ${ }^{31}$

\section{Diurnal Ventilation}

The respiratory muscles in patients with progressive NMDs will continue to weaken, and there may come a point when daytime ventilation support is needed. Clinical symptoms and symptoms that have been suggested for considering the need for diurnal ventilator support include elevated $\mathrm{CO}_{2}$ despite adequate nocturnal sleep therapy, diurnal dyspnea, and fatigue or difficulty concentrating. ${ }^{32}$ No absolute level of FVC or $\mathrm{P}_{\text {Imax }}$ has been identified to trigger the need for diurnal support because of the differences in natural history of the diseases. Careful, regular clinical assessment is advised.

Diurnal ventilation can be accomplished with mask ventilation and a bi-level device, tracheostomy, or via mouthpiece ventilation, which is a form of ventilation provided by a ventilator that delivers the breath to the patient via a mouthpiece interface (Fig. 2). In mouthpiece ventilation, the ventilator is generally set in the volume mode and the breath is delivered through a mouthpiece on demand when the patient places the mouthpiece interface in the mouth and makes a sip or "kiss" effort. The full tidal volume is delivered to the patient via the mouth, although there may be some small amount of leak from the mouth or nose. The patient is able to set their own minute ventilation and breathing frequency. In addition, the patient may perform breath-stacking by taking multiple breaths with mouthpiece ventilation, which can be an advantage in improving cough function. The patient is able to reach a higher lung volume than they would be able to on their own, thus increasing the volume of gas for cough. ${ }^{33}$

The choice of the device depends in large part on patient preference but also on the availability of expertise in each of the different types of ventilation, particularly mouthpiece ventilation. Fortunately, several manufacturers of home ventilators have now developed specific mouthpiece settings on their devices as well as adaptors for the interfaces for the ventilators, making it much easier to set this up in clinical practice. ${ }^{34,35}$ In some cases, where bulbar

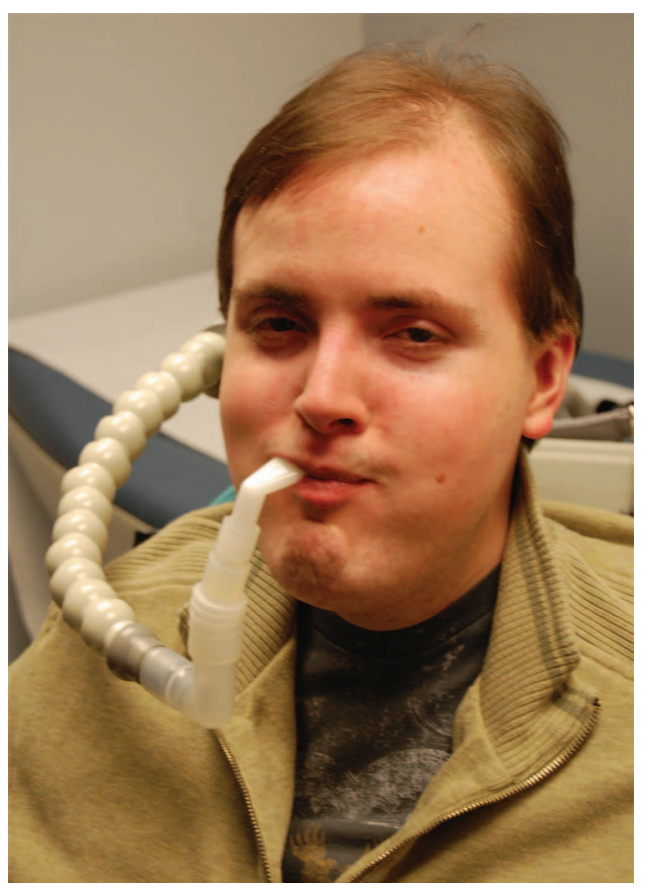

Fig. 2. Mouthpiece ventilation using angled mouthpiece and volume ventilator. With permission. From Reference 32.

involvement is too severe or NIV expertise is not available, tracheostomy placement will need to be considered.

\section{Cough Management}

As noted above, management of secretions is a major issue for patients with NMDs. It is at least as important to health and quality of life as the ventilatory support devices mentioned above. The measurement of cough peak flow on a regular basis is important to facilitate early detection of inadequate cough. Measurement in a clinic or in the pulmonary function lab is rapid and reproducible. A value of $<270 \mathrm{~L} / \mathrm{min}$ is suggested as the value below which cough-augmentation interventions should be considered. There are several ways in which the cough can be augmented. The first is through lung volume recruitment maneuvers where the patient stacks one breath on top of another. Breath-stacking can be accomplished either by glossopharyngeal breathing or through the use of a resuscitator bag, whereby an assistant can deliver repeated breaths with the patient retaining air by closing the glottis after the breath is delivered. This increases the gas volume allowing breath stacking in the lungs and results in a higher respiratory system elastic recoil pressure, thus increasing the cough peak flow. Some authors have suggested that measuring the maximum insufflation capacity (ie, the volume that can be obtained with breath-stacking along with the cough peak flow) can be a helpful measurement. ${ }^{36,37}$ If the maximal insufflation capacity cannot be raised signif- 

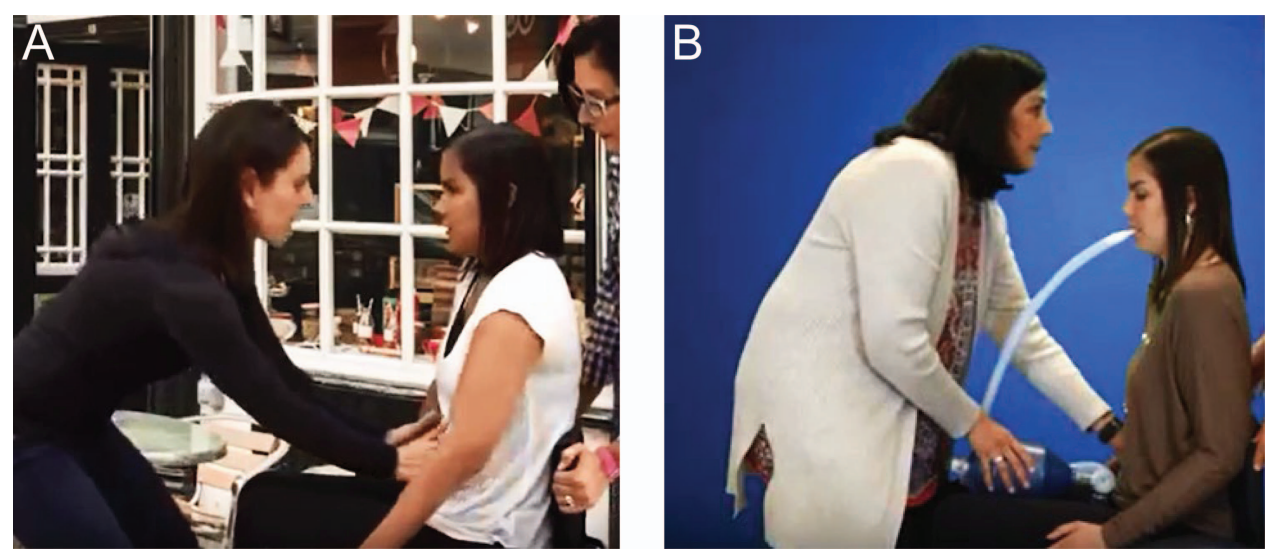

Fig. 3. Manually assisted cough. A: Without breath-stacking prior to cough. B: With breath-stacking prior to cough. With permission.

icantly above the patient's spontaneous vital capacity and generate a flow $>270 \mathrm{~L} / \mathrm{min}$, another cough-assistance modality will need to be used. ${ }^{38}$

A second method of increasing cough effectiveness is the manually assisted cough. In this maneuver, an abdominal or lateral ribcage thrust applied during the exhalation portion of the cough can increase the cough peak flow. The combination of breath-stacking using lung volume recruitment and manually assisted cough can be used together with results that are better than either alone (Fig. 3). ${ }^{33}$

If lung volume recruitment and manually assisted cough, either alone or together, are inadequate to generate cough peak flow $>270 \mathrm{~L} / \mathrm{min}$, a mechanical insufflation-exsufflation (MI-E) device can be used. This device is essentially an artificial cough generator that interfaces with the patient through a face mask or mouthpiece. It gives an inflating breath (insufflation) followed by a rapid negative pressure exhalation (exsufflation). The insufflation and exsufflation pressures can be adjusted to patient comfort and effectiveness in removing secretions from the airway. MI-E devices can generate some of the highest cough peak flows of the techniques mentioned. ${ }^{33,39}$

The most crucial time for the use of these techniques is during a respiratory tract infection. However, it is important that the patients and caregivers practice these maneuvers on a regular basis.

\section{Sialorrhea}

Sialorrhea in NMDs refers to the fact that patients with bulbar dysfunction have problems clearing saliva from the oropharynx. Sialorrhea is commonly seen in patients with ALS. This can be a very difficult situation because it can impair quality of life and cause choking, and it can make the use of NIV via mask or mouthpiece difficult or impossible. There are a number of medications that can be used when sialorrhea is an issue; Sahni and Wolfe ${ }^{8}$ pro- vide a summary of these medications in a recent review. Anticholinergic agents, such as glycopyrrolate, atropine, hyoscyamine sulfate, amitriptyline, and scopolamine, are a mainstay of therapy. Agents are available for oral, subcutaneous, and topical applications. They act by decreasing cholinergic input to the salivary glands, which reduce saliva output. These agents can thicken secretions, however, which can make mobilization somewhat more difficult, and they can have anti-cholinergic side effects including urinary retention, constipation, and diplopia. Glycopyrrolate does not cross the blood-brain barrier and is thus more commonly used. ${ }^{40}$

If medications are not effective, botulinum toxin injections have been used to decrease salivary output. The effect lasts several months and may be repeated. ${ }^{41}$ Salivary gland radiation and surgical removal have been tried for difficult cases, although the use of these techniques is not common. ${ }^{42}$

\section{Respiratory System Compliance}

The chest wall and lung in individuals with NMDs can exhibit reduced compliance over time due to changes in both due to disease sequelae. ${ }^{16,17}$ There has been a good deal of interest in methods to prevent or reverse this loss of compliance. The mainstay of these efforts has been a treatment to inflate the respiratory system by augmenting the inspiratory capacity above the volume that the patient can achieve without assistance. The thought is that this would be like a range of motion exercise as seen in physical therapy. ${ }^{43,44}$ The augmentation of inspiratory capacity has been accomplished through breath-stacking via glossopharyngeal breathing, use of a resuscitator bag, and a MI-E device, much like cough augmentation. In one shortterm study in subjects with NMD, a single session of 10 lung volume recruitment maneuvers increased total respiratory system compliance by approximately $40 \%$, although this returned to baseline after $1 \mathrm{~h} .{ }^{45}$ Unfortunately, 


\section{Respiratory CARe of Patients With NMD}

most of the longer-term data available are from prospective or retrospective cohort studies that have had mixed results and may be associated with a number of biases. ${ }^{46}$ Because lung volume recruitment maneuvers have a low risk associated with them, most experts suggest that patients perform these on a regular basis. ${ }^{27}$

\section{Summary}

A great deal of progress has been made in the respiratory treatment of patients with NMDs over the past 20 years. A great deal of this has come from gaining a better understanding of the pathophysiology of respiratory failure in these individuals and from the development of noninvasive technologies. Respiratory therapists are particularly able to participate in the treatment of these patients because the measurements and therapies involved are well known to them. The areas of measurement and support include ventilatory function as assessed by vital capacity, $\mathrm{P}_{\text {Imax }}$, or sniff nasal inspiratory pressure, and $\mathrm{P}_{\mathrm{ETCO}_{2}}$ or other measures of $\mathrm{CO}_{2}$. Ventilatory support is often noninvasive, with pressure support ventilation delivered via a mask interface at night and mouthpiece ventilation or tracheostomy ventilation during the day. Cough function is best assessed with cough peak flow, and a value $<270 \mathrm{~L} / \mathrm{min}$ while the patient is well suggests the need for cough assistance in the form of manually assisted cough, lung volume recruitment, or MI-E. Finally, lung volume recruitment maneuvers may help maintain lung function over time. Although few randomized trials with untreated controls have been performed, there is a large amount of data suggesting that life span for many of these individuals has been increased with these respiratory care interventions.

\section{REFERENCES}

1. Lefter S, Hardiman O, Ryan AM. A population-based epidemiologic study of adult neuromuscular disease in the Republic of Ireland. Neurology 2017;88(3):304-313.

2. Mier-Jedrzelowicz A, Brophy C, Moxham J, Green M. Assessment of diaphragm weakness. Am Rev Resp Dis 1988;137:877-883.

3. Morgan RK, McNally S, Alexander M, Conroy R, Hardiman O, Costello RW. Use of sniff nasal-inspiratory force to predict survival in amyotrophic lateral sclerosis. Am J Respir Crit Care Med 2005; 171(3):269-274.

4. Hukins CA, Hillman DR. Daytime predictors of sleep hypoventilation in Duchenne muscular dystrophy. Am J Respir Crit Care Med 2000;161(1):166-170

5. Leith DE, Butler JP, Sneddon SL, Brain JD. Cough. In: Macklem PT, Mead J, eds. Handbook of physiology: the respiratory system - volume III. Bethesda: American Physiologic Society, 1990;315336.

6. Tzani P, Chiesa S, Aiello M, Scarascia A, Catellani C, Elia D, et al. The value of cough peak flow in the assessment of cough efficacy in neuromuscular patients: a cross-sectional study. Eur J Phys Rehabil Med 2014;50(4):427-432.
7. Bach JR, Saporito LR. Criteria for extubation and tracheostomy tube removal for patients with ventilatory failure: a different approach to weaning. Chest 1996;110(6):1566-1571

8. Sahni AS, Wolfe L. Respiratory care in neuromuscular diseases. Respir Care 2018;63(5):601-608.

9. Aboussouan LS. Sleep-disordered breathing in neuromuscular disease. Am J Respir Crit Care Med 2015;191(9):979-989.

10. Mellies U, Ragette R, Schwake C, Boehm H, Voit T, Teschler H. Daytime predictors of sleep disordered breathing in children and adolescents with neuromuscular disorders. Neuromuscul Disord 2003;13(2):123-128.

11. Weinberg J, Klefbeck B, Borg J, Svanborg E. Polysomnography in chronic neuromuscular disease. Respiration 2003;70(4):349-354.

12. Appelberg J, Nordahl G, Janson C. Lung volume and its correlation to nocturnal apnoea and desaturation. Respir Med 2000;94(3):233239.

13. Cirignotta F, Mondini S, Zucconi M, Barrot-Cortes E, Sturani C, Schiavina M, et al. Sleep-related breathing impairment in myotonic dystrophy. J Neurol 1987;235(2):80-85.

14. Dauvilliers YA, Laberge L. Myotonic dystrophy type 1, daytime sleepiness and REM sleep dysregulation. Sleep Med Rev 2012;16(6): 539-545.

15. Steier J, Jolley CJ, Seymour J, Teschler H, Luo YM, Polkey MI, et al. Screening for sleep-disordered breathing in neuromuscular disease using a questionnaire for symptoms associated with diaphragm paralysis. Eur Respir J 2011;37(2):400-405

16. De Troyer A, Borenstein S, Cordier R. Analysis of lung volume restriction in patients with respiratory muscle weakness. Thorax 1980; 35(8):603-610.

17. Estenne M, Heilporn A, Delhez L, Yernault JC, De Troyer A. Chest wall stiffness in patients with chronic respiratory muscle weakness. Am Rev Respir Dis 1983;128(6):1002-1007.

18. Baydur A, Milic-Emili J. Respiratory mechanics in kyphoscoliosis. Monaldi Arch Chest Dis 1993;48(1):69-79.

19. Clinical indications for noninvasive positive pressure ventilation in chronic respiratory failure due to restrictive lung disease, COPD, and nocturnal hypoventilation-a consensus conference report. Chest 1999; 116(2):521-534.

20. Nicholson TT, Smith SB, Siddique T, Sufit R, Ajroud-Driss S, Coleman JM 3rd, et al. Respiratory pattern and tidal volumes differ for pressure support and volume-assured pressure support in amyotrophic lateral sclerosis. Ann Am Thorac Soc 2017;14(7):1139-1146.

21. Martinez D, Sancho J, Servera E, Marin J. Tolerance of volume control noninvasive ventilation in subjects with amyotrophic lateral sclerosis. Respir Care 2015;60(12):1765-1771.

22. Hess DR. Noninvasive ventilation in neuromuscular disease: equipment and application. Respir Care 2006;51(8):896-911.

23. Hess DR. Noninvasive ventilation for neuromuscular disease. Clin Chest Med 2018;39(2):437-447.

24. Nava S. Behind a mask: tricks, pitfalls, and prejudices for noninvasive ventilation. Respir Care 2013;58(8):1367-1376.

25. Nava $\mathrm{S}$, Navalesi $\mathrm{P}$, Gregoretti C. Interfaces and humidification for noninvasive mechanical ventilation. Respir Care 2009;54(1):71-84.

26. Berry RB, Chediak A, Brown LK, Finder J, Gozal D, Iber C, et al. Best clinical practices for the sleep center adjustment of noninvasive positive pressure ventilation (NIV) in stable chronic alveolar hypoventilation syndromes. J Clin Sleep Med 2010;6(5):491-509.

27. McKim DA, Road J, Avendano M, Abdool S, Cote F, Duguid N, et al. Home mechanical ventilation: a Canadian Thoracic Society clinical practice guideline. Can Respir J 2011;18(4):197-215.

28. Bourke SC, Tomlinson M, Williams TL, Bullock RE, Shaw PJ, Gibson GJ. Effects of non-invasive ventilation on survival and quality of life in patients with amyotrophic lateral sclerosis: a randomised controlled trial. Lancet Neurol 2006;5(2):140-147. 


\section{Respiratory CARE of PATIENTS With NMD}

29. Eagle M, Baudouin SV, Chandler C, Giddings DR, Bullock R, Bushby K. Survival in Duchenne muscular dystrophy: improvements in life expectancy since 1967 and the impact of home nocturnal ventilation. Neuromuscul Disord 2002;12(10):926-929.

30. Eagle M, Bourke J, Bullock R, Gibson M, Mehta J, Giddings D, et al. Managing Duchenne muscular dystrophy: the additive effect of spinal surgery and home nocturnal ventilation in improving survival. Neuromuscul Disord 2007;17(6):470-475.

31. Hill NS. Noninvasive positive pressure ventilation in neuromuscular disease. Enough is enough! Chest 1994;105(2):337-338.

32. Benditt JO, Boitano LJ. Pulmonary issues in patients with chronic neuromuscular disease. Am J Respir Crit Care Med 2013;187(10): 1046-1055

33. Senent C, Golmard JL, Salachas F, Chiner E, Morelot-Panzini C, Meninger $\mathrm{V}$, et al. A comparison of assisted cough techniques in stable patients with severe respiratory insufficiency due to amyotrophic lateral sclerosis. Amyotroph Lateral Scler 2011;12(1):26-32.

34. Boitano LJ, Benditt JO. An evaluation of home volume ventilators that support open-circuit mouthpiece ventilation. Respir Care 2005; 50(11):1457-1461.

35. Khirani S, Ramirez A, Delord V, Leroux K, Lofaso F, Hautot S, et al. Evaluation of ventilators for mouthpiece ventilation in neuromuscular disease. Respir Care 2014;59(9):1329-1337.

36. Kang SW, Bach JR. Maximum insufflation capacity: vital capacity and cough flows in neuromuscular disease. Am J Phys Med Rehabil 2000;79(3):222-227.

37. Kang SW, Choi WA, Won YH, Lee JW, Lee HY, Kim DJ. Clinical implications of assisted peak cough flow measured with an external glottic control device for tracheostomy decannulation in patients with neuromuscular diseases and cervical spinal cord injuries: a pilot study. Arch Phys Med Rehabil 2016;97(9):1509-1514.
38. Ishikawa Y, Bach JR, Komaroff E, Miura T, Jackson-Parekh R Cough augmentation in Duchenne muscular dystrophy. Am J Phys Med Rehabil 2008;87(9):726-730.

39. Bach JR, Smith WH, Michaels J, Saporito L, Alba AS, Dayal R, et al. Airway secretion clearance by mechanical exsufflation for postpoliomyelitis ventilator-assisted individuals. Arch Phys Med Rehabil 1993;74(2):170-177.

40. Squires N, Wills A, Rowson J. The management of drooling in adults with neurological conditions. Curr Opin Otolaryngol Head Neck Surg 2012;20(3):171-176.

41. Banfi P, Ticozzi N, Lax A, Guidugli GA, Nicolini A, Silani V. A review of options for treating sialorrhea in amyotrophic lateral sclerosis. Respir Care 2015;60(3):446-454.

42. Neppelberg E, Haugen DF, Thorsen L, Tysnes OB. Radiotherapy reduces sialorrhea in amyotrophic lateral sclerosis. Eur J Neurol 2007;14(12):1373-1377.

43. Katz SL, Barrowman N, Monsour A, Su S, Hoey L, McKim D. Long-term effects of lung volume recruitment on maximal inspiratory capacity and vital capacity in Duchenne muscular dystrophy. Ann Am Thorac Soc 2016;13(2):217-222.

44. McKim DA, Katz SL, Barrowman N, Ni A, LeBlanc C. Lung volume recruitment slows pulmonary function decline in Duchenne muscular dystrophy. Arch Phys Med Rehabil 2012;93(7):1117-1122.

45. Molgat-Seon Y, Hannan LM, Dominelli PB, Peters CM, Fougere RJ, McKim DA, et al. Lung volume recruitment acutely increases respiratory system compliance in individuals with severe respiratory muscle weakness. ERJ Open Res 2017;3(1).

46. Sheers N, Howard ME, Berlowitz DJ. Respiratory adjuncts to NIV in neuromuscular disease. Respirology 2018 [Epub ahead of print] doi: 10.1111/resp.13431.

\section{Discussion}

Hill: That was great, per usual, Josh. Your last comment leads to my comment, which is that one of the big frustrations we've had-and I'm sure you share this as well-is that because of the tenuous funding in the durable medical equipment field, the availability of really skilled respiratory therapists who understand the pathophysiology and the equipment that is involved is quite unreliable. And it changes almost every few months because the therapists either go into industry or are hired by some other company and then the patient is left hanging. It's a real frustration.

Benditt: I would agree, there's a huge problem. I remember Sam Giordano talking about this back in the 90s, that the respiratory therapist (RT) in the home does not get paid for the work that they do in the home-it's bundled into the payments for devices.
And because of the issues of rentals that are capped and so forth, patients may not be getting at all what they need at home. That is a big question and I'm sure the AARC is dealing with that even at this moment, but it's terrible. And so what I've done is, we in our community have tried to identify one therapist at each company who will take responsibility for it. We use the approach of, "We'd love to use your company, we have all these patients, we need your help with this," so that we can get people out into the home more quickly. It's a big problem.

* Kallstrom: The problem is even worse now, especially with $\mathrm{O}_{2}$ patients, the reimbursement from CMS (Centers for Medicare and Medicaid Services) is almost nonexistent and the $\mathrm{O}_{2}$ is delivered by a delivery person or even

* Thomas J Kallstrom RRT MBA FAARC, Executive Director, American Association for Respiratory Care.
UPS. There was a survey done by Susan Jacobs with the ATS ${ }^{1}$ that patients are frustrated with this and they have nowhere to turn. We need to fix this, and certainly the AARC and others are trying to turn this around, but it's a huge problem. Not just for noninvasive ventilation but for $\mathrm{O}_{2}$ as well; we have to put RTs back into the home and let them provide the skilled care and education that they need to.

Benditt: I've had great RTs over the years, really fabulous people working with me, and they really love it because unlike the intensive care unit, where you come in and you do your shift and then the patient is gone and you don't get to follow, they follow these patients for years and it's very rewarding for them. Louis Boitano, who I used to work with, absolutely loved this and would do home visits. I totally agree, there would be good job satisfaction and better patient care. And you know, Nick [Hill], that in 
terms of respiratory assist device (RAD) versus the ventilator, it's created distortions where people will prescribe a full ventilator rather than a RAD because the only way they can get somebody into the home is with a ventilator. That is the craziest thing because the ventilator is more expensive.

Hill: It's a perverse incentive, for sure.

Strickland: I'm going to date myself a little bit here, but back in the day we used to manage our NMD patients with negative-pressure ventilators. My clinical background is mostly pediatrics, so I remember a time when we had a physician who had been around for a very long time and was very insistent on some sort of noninvasive ventilation, usually an iron lung, for his patients and really did not like tracheostomies at all for those patients, and it was interesting to see the fairly good quality of life that these patients had after years and years of negative-pressure ventilation. So to watch those patients transition over to positive pressure NIV was interesting, and we used to put both on for a short period of time on some of our patients. This brought back a few memories of our teenage and early 20s long-term NMD patients with their very unique systems.

Benditt: Absolutely, don't let Nick fool you, he was the spokesmodel for the Port-A-Lung; he had pictures in those and iron lungs and pneumo suits, and we actually had a few patients who would not give up their negative-pressure ventilator in going from pediatrics to adult, and because of the frequency of upper airway obstruction, I had patients who were treated with a poncho or a pneumo suit and CPAP for some time.

$\uparrow$ Branson: I want to follow on what Tom [Kallstrom] said. The survey by

\footnotetext{
$\dagger$ Richard D Branson MSc RRT FAARC, Editor in Chief, Respiratory CARE.
}

Jacobs et $\mathrm{al}^{1}$ showed that nearly two thirds of patients never got their $\mathrm{S}_{\mathrm{pO}_{2}}$ measured before they had their $\mathrm{O}_{2}$ delivered at home. Also, in two thirds of patients, the $\mathrm{O}_{2}$ was set up by the guy who drives the truck and not by a health care practitioner in any way shape or form. That's all driven by this competitive bidding process, and I think they're trying to move ventilators in that direction as well. I know of places where the companies are taking over home ventilation in a competitive bidding market and are calling and are saying that patient can't be on a ventilator anymore, they have to go on a RAD. Even though it's impossible for the patient to actually do that. I'm an acute care person and I don't know what the answer is, but what's the status of respiratory care and Medicare Part B and getting reimbursement? Is it just a dog that won't hunt, or is it still an active goal?

* Kallstrom: We're still pushing it. We have a fantastic lobbyist team up in Washington D.C., and Anne Marie Hummel is great at what she does. We also did a survey of RTs in the hospital to find out what they were doing to prepare the patient for home. Does the RT even know the equipment that they're going home on? And by and large, it depended on how long they had been in the profession-the longer they had been in the profession, the more likely they were to be able to transition these patients better. I think until we get this problem fixed, we need to get the hospital-based RT to be better educated so that they can prepare these patients when they go home and not have a UPS driver drop it off at the house, which is sadly what's happening.

MacIntyre: I don't have a question, more an observation because I've been watching this home NIV issue for the past 25 years. The problem involves reimbursement rules for home NIV based upon whether the NIV device is considered by Medicare to be a ven- tilator or a RAD. For the life of me, I cannot figure out from any engineering principles what the difference is between a RAD and a ventilator. Indeed, Medicare offers no engineering design criteria and bases the distinction entirely on the therapeutic intent. Any good therapist can take a BPAP S/T NIV system and ventilate an ICU patient with an appropriately designed endotracheal tube connector. In contrast, most modern ICU ventilators have full capabilities for mask ventilation support. Again, I think the problem is that Medicare and others are trying to force some kind of artificial engineering distinction on what really is a clinical goals issue and then determine payment accordingly. I'd be interested to hear from people here who deal with this more than I do. The Europeans seem to me may have the right answer here; they don't call it a RAD or a ventilator, they simply describe everything as a positive pressure device used in the home to support ventilation and/or oxygenation, and the reimbursement scale is based on the number of hours they need to use it. So someone who really needs high intensity life support for most or all of the day would qualify for the highest reimbursement, while somebody who only needs a device for $8 \mathrm{~h}$ at night would get a lower reimbursement. Importantly, all reimbursement includes payment for professional support. I think we mire ourselves down in great confusion and conflict when we keep trying to force some kind of engineering distinction on what is really a clinical goals situation.

Hill: It is absurd, and as you know, Neil, the National Association for Medical Direction of Respiratory Care has gotten down into the weeds on this one. I have been a participant in that, and when we last met face to face with CMS on these issues, I referred to the bi-level type devices as ventilators and one of the CMS panelists corrected me and told me that a bi-level is not a ventilator. I referred 
him to my Respiratory CARE article from $1990^{2}$ that established BPAP as a pressure-limited ventilator, and he referred me to an act of Congress that apparently says otherwise.

MacIntyre: And just to clarify, the FDA does not recognize the concept of RAD in their classification of devices. It exists nowhere in their lexicon.

+ Hess: I think it also sends a message to our patients. I've had patients who've been on a bi-level device 24/7 for ALS and they were told they were not on a ventilator, but others who were managed with an intermediate device were said to be on a ventilator. For patients and families receiving the same therapy but one is called a ventilator and one is not, it has different connotations. The one who's on the ventilator thinks, "I'm going to die" versus the other is thinking, "well, this isn't so bad."

MacIntyre: It is interesting that Congress is defining our respiratory devices and we, in the clinical arena with our clinical data, are dismissed.

Scott: For the last couple of months I've been reading quite a bit about ventilators that can provide NIV. I will tell you, Neil, that I really appreciate your comment, because for the life of me I can hardly tell the difference either. I feel like I'm missing something. I keep reading and reading more and more whether it's a turbine versus some other pneumatics, but at the end of the day it's about what we're trying to actually do for the patients.

MacIntyre: There are new ventilators being based on turbine technology, so the turbine doesn't do it, the expiratory valve doesn't do it, there really is no engineering line in the sand between a so-called RAD and a so-

$\ddagger$ Dean R Hess PhD RRT FAARC, Managing Editor, RESPIRATORY CARE. called ventilator, except perhaps in the minds of the members of Congress. Which I think speaks volumes about the situation.

Benditt: They may falsely assume that a ventilator is a life-support device versus a RAD being non-life support.

MacIntyre: But again, that speaks to the clinical goal and has nothing with the engineering design.

Benditt: I completely agree, it's artificial and it creates all kinds of distortions in the system.

Hill: One of the things you brought up in your talk was your fourth pillar of pathophysiology dealing with loss of chest wall compliance, and I agree with you that many NMD patients suffer from stiffness of the chest wall. The treatment of this, however, is problematic. You kind of raised the suspense and said, "I'll show you later." But I have to say that the evidence you showed us doesn't have me very convinced.

Benditt: There are not a lot of data, but I think there will be more coming out because there are some studies in Europe looking at this. The lung volume recruitment maneuvers are pretty easy to do, they're quite cheap in that the resuscitator bag is like $\$ 20$, and if you're on mouthpiece ventilation you can do it very easily during the day. So I think because it's a very low cost intervention, I instruct my patients to do it. Now, I would agree that the data supporting the use are not great. But hopefully we'll have more. In the beginning there weren't terrific data for bi-level either when we first started using it.

Hill: I tell people to use their cough assist twice a day; I don't use breathstacking that often. I tell them because I want them to stay in practice with their cough assist so I never again hear the mother of a kid with Duchenne muscular dystrophy who had just died of mucus plugging tell me that she forgot to use the cough assist because it was in the closet.

Benditt: Absolutely important point, the MI-Es (mechanical insufflation-exsufflation) devices get stuck in the closet, but they can be used as lung volume recruitment devices daily. The currently available devices allow you to do multiple settings on the MI-E, so you can do one that's just a recruitment and then one that's just a cough. Again, you're right, there are not a lot of data, but I think it's being thought about more by the people who do this all the time.

$\$$ Hess: It's important to point out that with a pressure-limited bi-level device, you cannot do breath-stacking. I've seen that mistake made. You need to use an MI-E device or a resuscitator bag as you showed, or a volume mode on the ventilator to do that.

Benditt: Yes. So people say can you do mouthpiece ventilation with a pressure-limited device, and it's possible, although the current pressure devices don't do it well, they auto-cycle and all kinds of things. But you cannot do breath-stacking, and what I've found for mouthpiece ventilation is the ability to cough on your own without an attendant doing something to you is incredibly valuable, and that's why taking multiple breaths and getting higher chest wall recoil . . I I didn't go into all that, but the cough is much better.

\section{REFERENCES}

1. Jacobs SS, Lindell KO, Collins EG, Garvey $\mathrm{CM}$, Hernandez C, McLaughlin S, et al. Patient supplemental oxygen survey: results of the American Thoracic Society Nursing Assembly Oxygen Working Group. Am J Respir Crit Care Med 2017; 195:A7645.

2. Strumpf DA, Carlisle CC, Millman RP, Smith KW, Hill NS. An evaluation of the Respironics BiPAP bi-level CPAP device for delivery of assisted ventilation. Respir Care 1990;35:415-422. 